\title{
Intradermal DNA vaccination in ear pinnae is an efficient route to protect cats against rabies virus
}

\author{
Emiliano Tesoro-CRUZ ${ }^{1,2 *}$, Rafael CALDERón-RodríGUEZ ${ }^{1,2,}$, \\ Rafael HERnÁNDEZ-GonzÁlez ${ }^{2}$, Francisco Blanco-FAvéla ${ }^{1}$, \\ Alvaro Aguilar-SeTIÉN ${ }^{1}$
}

\author{
${ }^{1}$ Unidad de Investigación Médica de Alta Especialidad en Inmunología, IMSS, México DF \\ ${ }^{2}$ Departamento de Investigación Experimental y Bioterio del Instituto Nacional de Ciencias Médicas y Nutrición \\ "Salvador Zubirán" (INCMNSZ), México DF
}

(Received 8 February 2007; accepted 11 October 2007)

\begin{abstract}
A DNA vaccine against rabies (pGQH) was administrated to cats in order to examine different administration routes. Four groups of three cats each were inoculated with $\mathrm{pGQH}$ as follows: group A, intramuscularly (IM), $100 \mu \mathrm{g}$; group B, intranasally (IN), $100 \mu \mathrm{g}$; group C, intradermally into ear pinnae (ID-EP), $100 \mu \mathrm{g}$, and group D, IM, $200 \mu \mathrm{L}$ of phosphate buffer solution (PBS) alone (control group). Blood was drawn on days $0,30,60,90,120,150$, and 180. Groups A, B, and C received a booster on day 30 . At day 200 all animals were challenged. A passive transfer of cat sera, as well as a viral challenge, was performed in mice. The results displayed that neutralizing antibody titers were higher in cats of group C (ID-EP) showing high early titers (> 2 IU) and the highest titer was on day 120 (> 14 IU). In group B (IN), two out of three cats seroconverted on day 30 (>0.5 IU), the third cat seroconverted until day 60 ( $>0.5 \mathrm{IU})$. In contrast, the lowest levels of neutralizing antibodies were detected in group A (IM). The control group showed no anti-rabies antibodies. Groups A (IM) and D (control) succumbed after lethal challenge. All animals from the ID-EP group (C) survived, only one individual from the IN (B) group died. Mice that received cat sera from ID-EP, IM, and IN groups survived and were protected (30/30 survivors). Mice groups that received pre-immunization sera from cats were not protected ( $0 / 30$ survivors). This study demonstrates that $\mathrm{pGQH}$ immunization was successful when it was administrated ID-EP, and acceptable through the IN route. The IM route, however, was not effective in cats. For vaccination, the IN route seems attractive due to its accessibility for application, but it seems to activate seroconversion slowly. The best route to promote anti-rabies antibody titers was the ID-EP route. This practical and efficient route should be further studied.
\end{abstract}

rabies / DNA vaccine / intradermal into ear pinna / intranasal / cats

\section{INTRODUCTION}

Rabies is an infection which may affect humans and wild and domestic homeothermic animals, causing lethal encephalitis [1]. The infection usually occurs through broken skin or mucosa exposed to saliva or neural tissue from a rabid animal [1]. Epidemic data

\footnotetext{
* Corresponding author:

emiliano_tesoro@hotmail.com
}

demonstrates that the number of human rabies deaths worldwide is estimated from 40000 to as high as 70000 per year [26]. Ninety-eight percent of the cases occur in developing countries (Asia, Africa, and Latin America) and, although the disease has been controlled in domestic animals in many developed countries, rabies still causes significant animal losses and public health problems worldwide. It is 
estimated that at least 50 million dogs are vaccinated each year against rabies in private practices or during national campaigns organized by ministries of health or agriculture. Unfortunately, in developing countries where dogs are the most important viral reservoir, the $30-50 \%$ vaccination coverage of the canine population that is annually done is not enough to break the disease' transmission cycle [26].

Cats are considered companion animals and they may transmit rabies to humans. In fact, in Quintana Roo, Mexico, in 2006, a case of a human death was reported [18] when a stray cat bit a child. The diagnosis was confirmed postmortem by the Reference Laboratory of the Ministry of Health of Mexico (INDRE, SSA), and the autopsy confirmed encephalitis caused by the rabies virus belonging to the antigenic variant V-3, which corresponds to a bat specific variant. This means that the stray cat may have acquired rabies from the bite of a bat [18].

Domestic animal rabies (especially in dogs and cats) has been controlled by traditional parenteral vaccination, but wild animal rabies has been more difficult to control due to host inaccessibility. It, thus, remains an important problem for public health $[8,35]$. Poor vaccination coverage, sometimes with inferior quality vaccines that fail to maintain persistent levels of neutralizing antibodies, in addition to the difficulty in re-locating stray dogs for booster vaccinations, suggests that an inexpensive rabies vaccine eliciting a long-term protection after a one-time vaccination might facilitate the control of rabies in developing countries [23].

A new methodology for fox immunization against rabies was developed after the 1970s. The vaccines studied (attenuated) were SAD Bern, SAG2, SAD B19, and more recently the recombinant VRG vaccinia rabies. These were orally administrated first using chicken-head baits and later more evolved baits, leading to the virtual elimination of wild fox rabies in Western Europe [31]. Several inactivated rabies vaccines are commercially available for domestic animals and it has been demonstrated that these vaccines induce protective immune responses after a single vacci- nation. However, such vaccines carry certain risks due to the possibility of an incomplete inactivation of the virus or the inadvertent spread of residual rabies virus pathogenic particles [36]. Furthermore, some rabies vaccines have been associated with injection-site fibrosarcomas in cats [34]. These problems have led to continued efforts to develop safer rabies vaccines using recombinant subunit proteins [39], recombinant viral vectors [30,41], and deoxyribonucleic acid (DNA) based vaccines $[10,13,33,40]$.

DNA immunizations have some advantages over traditional vaccines: they are safer for at no time the rabies virus is handled, and they induce cell-mediated and humoral immune responses. Different inoculation routes for DNA vaccines have been explored, but efficacy varies depending on the animal model and the inoculation route [33]. Recently, intradermal DNA vaccination into the ear pinna route has been reported to produce high levels of neutralizing antibodies in dogs [22]. The intranasal (IN) route has been drawing attention in the use of genetic vaccines and in other genetic therapy fields [28].

The epithelial surface of the nasal lymphoid tissue (NALT) contains specialized antigen sampling cells that transport antigens from the mucosal surfaces into the underlying lymphoid tissues [16]. After entering into the NALT, antigens are rapidly internalized and processed by subepithelial dendritic cells and macrophages, and are presented to the B and T cells located in the NALT [16]. In a previous report, we demonstrated the possibility of vaccinating vampire bats by aerosol, using a recombinant vaccinia-rabies virus [2]. Another study was performed in dogs by the IN route using a DNA vaccine [38]. Furthermore, Oh et al. demonstrated that DNA vaccines are efficient by the intranasal route [28]. Osorio et al. [29] reported the use of intradermal infection into ear pinnae (ID-EP) as a very good route to administrate a DNA vaccine against rabies in dogs. The aim of this study was to evaluate the antibody response and protection induced by a DNA vaccine against the rabies virus administered to cats by intramuscular, intranasal, and intradermal into ear pinna routes. 


\section{MATERIALS AND METHODS}

\subsection{Viruses and cells}

BHK-21 cells were grown in Eagle minimal essential medium (MEM) containing 10\% fetal bovine serum (FBS) during growth phase, and $2 \%$ during stationary phase, as previously described [17]. Challenge virus standard (CVS) strain was maintained by inoculation in Balb/c suckling mice.

The HQ01-IMSS Mexican rabies isolate was used to design the vaccine plasmid. It was obtained from a child who died of rabies transmitted from a vampire bat. This case occurred during an outbreak that took place in Tejupilco $(200 \mathrm{~km}$ from Mexico City) in 2000, when livestock breeding was substituted by sugar cane growth and vampire bats tried to feed on humans. This isolate was maintained in Balb/c suckling mice and it corresponds to the rabies aerial cycle when analyzed by restriction fragment length polymorphism (RFLP) [24].

When it was analyzed under the classification of the monoclonal antibody panel from the Center for Disease Control (CDC, Atlanta, USA), the results showed that it corresponded to variant 8 . This isolate has not been the object of any particular publication.

\subsection{Plasmid construction}

The DNA vaccine against rabies was constructed following technical procedures previously described by Bahloul et al. [6] and Perrin et al. [33]. It consists of a mammalian expression vector $\mathrm{pCl}$ neo (Promega Corporation, Madison, WI., USA) into which the glycoprotein-encoding gene of the HQ01-IMSS virus [3] was inserted (pGQH). This vaccine has a potent eukaryotic promoter from the Cytomegalovirus and by parenteral route, led to a high antibody titer and protection against rabies in mice and dogs [38].

Comparing two sequences using the Pasteur virus strain as reference, we found 12 amino acid substitutions in the HQ01-IMSS Mexican rabies virus isolate, but they were not located in any important antigenic site: 71, 139, 175, 177, 274, 297, 358, 407, 427, 444, 473, and 480 amino acids. Therefore, these substitutions should not have important antigenic differences.

\subsection{Plasmid production}

The pGQH was grown in Escherichia coli (DH10B). Bacteria were cultivated in Luria medium (Triptona $1 \%$, extract of yeast $0.5 \%$, and $\mathrm{NaCl} 1 \%$ ) and $100 \mu \mathrm{g} / \mathrm{mL}$ of ampicilin were added to $2.5 \mathrm{~L}$ of $\mathrm{LB}$ medium. After $24 \mathrm{~h}$ growth, $\mathrm{pGQH}$ was purified using the commercial system Endofree Plasmid Giga Kit (Qiagen, Hilden, Germany).

\subsection{Cats}

Twelve cats (Creole, females and males between one and two years old, $2-3 \mathrm{~kg}$ ) free of anti-rabies antibodies were used.

The cats were randomly assigned to four experimental groups A, B, C, and D (three cats per group). They were exercised daily, fed commercial cat food $\left(\right.$ Whiskas ${ }^{\circledR}$ ) and received water ad libitum. The cats had previously received calicivirus, rhinotracheitis, and panleucopenia feline vaccinations (Feligen, Laboratoire Virbac, Carros, France), but they had not been vaccinated against rabies. All cats were healthy and were housed indoors, with artificial light. The animals were kept in two common cages $(2.5 \times 3 \times 2.20 \mathrm{~m})$, one for females and the other one for males. After challenge, 200 days after vaccination, each common cage was divided into two spaces, and the cats were separated into groups of three, one group in each space. When the cats showed the first unmistakable signs of rabies, they were taken out of the cage and put into individual cages. This took place in an animal facility at the Instituto Nacional de Ciencias Médicas y Nutrición "Salvador Zubirán" (INCMNSZ). The Animal Resources Laboratory, the animal care, and programs used at the INCMNSZ were fully accredited by the Office of Laboratory Animal Welfare (OLAW) of the USA Public Health Services, under the animal welfare assurance \# A5600-1.

\subsection{Mice}

To study the passive transfer of cat sera to mice, we used $66 \mathrm{Balb} / \mathrm{c}$ female eight week old mice, from the animal facility at the INCMNSZ. Six of them were used to study the average life of passively-transferred cat rabies virus neutralizing antibodies to mice. The other 60 were used to study the passive transfer of cat sera to mice.

\subsection{Immunization and bleeding of cats}

The cats were assigned to four experimental groups (A, B, C, and D) (Tab. I).

Before inoculation, all animals were bled for control serum samples (previous to immunization). The cats were bled 15, 30, 60, 90, 120, 150, and 
Table I. Cat inoculation protocol.

\begin{tabular}{lccccccc}
\hline Group & $\begin{array}{c}\text { Cat } \\
\text { number }\end{array}$ & Sex $^{1}$ & $\begin{array}{c}\text { Age } \\
\text { (months) }\end{array}$ & $\begin{array}{c}\text { Route of } \\
\text { inoculation }\end{array}$ & $\begin{array}{c}\text { Product } \\
\text { inoculated } \\
\text { (quantity) }\end{array}$ & $\begin{array}{c}\text { Number } \\
\text { of } \\
\text { sites }\end{array}$ & $\begin{array}{c}\text { Booster } \\
\text { (quantity/day) }\end{array}$ \\
\hline A & 1 & F & 12 & IM $^{2}$ & Plasmid $(100 \mu \mathrm{g})$ & 2 & $100 \mu \mathrm{g} / 30$ \\
& 2 & M & 12 & IM & Plasmid $(100 \mu \mathrm{g})$ & 2 & $100 \mu \mathrm{g} / 30$ \\
B & 3 & F & 16 & IM & Plasmid $(100 \mu \mathrm{g})$ & 2 & $100 \mu \mathrm{g} / 30$ \\
& 4 & M & 12 & IN $^{3}$ & Plasmid $(100 \mu \mathrm{g})$ & 2 & $100 \mu \mathrm{g} / 30$ \\
& 5 & F & 15 & IN & Plasmid $(100 \mu \mathrm{g})$ & 2 & $100 \mu \mathrm{g} / 30$ \\
C & 6 & F & 16 & IN & Plasmid $(100 \mu \mathrm{g})$ & 2 & $100 \mu \mathrm{g} / 30$ \\
& 7 & F & 16 & ID-EP & Plasmid $(100 \mu \mathrm{g})$ & 2 & $100 \mu \mathrm{g} / 30$ \\
& 8 & F & 18 & ID-EP & Plasmid $(100 \mu \mathrm{g})$ & 2 & $100 \mu \mathrm{g} / 30$ \\
D & 9 & M & 24 & ID-EP & Plasmid $(100 \mu \mathrm{g})$ & 2 & $100 \mu \mathrm{g} / 30$ \\
& 10 & M & 24 & IM & PBS $(200 \mu \mathrm{L})$ & 1 & - \\
& 11 & M & 18 & IM & PBS $(200 \mu \mathrm{L})$ & 1 & - \\
\hline
\end{tabular}

${ }^{1} \mathrm{M}$ : male, F: female.

${ }^{2}$ Intramuscularly in the quadriceps.

${ }^{3}$ Intranasally by instillation.

${ }^{4}$ Intradermally in the ear pinnae.

Table II. Cat challenge.

\begin{tabular}{lccc}
\hline Cat number & Group/Route & Product inoculated (quantity) & Challenge results \\
\hline 1 & A-IM & Plasmid $(100 \mu \mathrm{g})$ & Death \\
2 & A-IM & Plasmid $(100 \mu \mathrm{g})$ & Death \\
3 & A-IM & Plasmid $(100 \mu \mathrm{g})$ & Death \\
4 & B-IN & Plasmid $(100 \mu \mathrm{g})$ & Survive \\
5 & B-IN & Plasmid $(100 \mu \mathrm{g})$ & Death \\
6 & B-IN & Plasmid $(100 \mu \mathrm{g})$ & Survive \\
7 & C-ID-EP & Plasmid $(100 \mu \mathrm{g})$ & Survive \\
8 & C-ID-EP & Plasmid $(100 \mu \mathrm{g})$ & Survive \\
9 & C-ID-EP & Plasmid $(100 \mu \mathrm{g})$ & Survive \\
10 & D-IM/PBS & PBS $(200 \mu \mathrm{L})$ & Death \\
11 & D-IM/PBS & PBS $(200 \mu \mathrm{L})$ & Death \\
12 & D-IM/PBS & PBS $(200 \mu \mathrm{L})$ & Death \\
\hline
\end{tabular}

180 days after the initial vaccination. Animals from groups $\mathrm{A}, \mathrm{B}$, and $\mathrm{C}$ received a booster one month after the first vaccination (same doses and routes). On day 200 all cats were challenged (Tab. II).

To take blood samples from the cats, they were anesthetized (Ketamine-Xylacine, $22 \mathrm{mg} / \mathrm{kg}$ $1.1 \mathrm{mg} / \mathrm{kg}$, respectively, IM). All serum samples were stored at $-20{ }^{\circ} \mathrm{C}$.

\subsection{Rabies virus neutralizing antibodies}

Virus neutralizing antibody titers (VNAb) were determined using the rapid fluorescent focus inhibition test (RFFIT) and the results were expressed in international units (IU)/mL of rabies virus neu- tralizing antibodies (protective titer $=0.5 \mathrm{IU} / \mathrm{mL}$ ) as described by Smith et al. [37]. A rabies hyperimmune dog serum and a standard human rabies immunoglobulin with known IU were included as positive controls in all assays. Three folded serial dilutions of both the serum samples and the controls (positive and negative), were prepared in microplates; each serum dilution was added to four adjacent wells. A dilution of $50 \mu \mathrm{L}$ of CVS strain containing from 15 to 30 fluorescent foci was also added to each well. After $60 \mathrm{~min}$ of incubation at $37{ }^{\circ} \mathrm{C}$ in a humidified incubator with $5 \% \mathrm{CO}_{2}$, a $50 \mu \mathrm{L}$ volume of the cell suspension, containing $4 \times 10^{5}$ cells $/ \mathrm{mL}$, was added to each well, and the plates were incubated for $48 \mathrm{~h}$ at $37{ }^{\circ} \mathrm{C}$. After 
fixation for $30 \mathrm{~min}$ at room temperature in $80 \%$ acetone, the microplates were stained by adding $100 \mu \mathrm{L}$ of FITC anti-rabies antibody (1:50 dilution) (Cat. No. 5100, Chemicon International, Temecula, CA, USA) to each well. Staining was carried out in an incubator at $37^{\circ} \mathrm{C}$ for $30 \mathrm{~min}$.

\subsection{Western blot}

Western blot tests were applied to all serum samples. These were made using partially purified rabies glycoprotein [5].

The glycoprotein does not correspond to the Mexican isolate. It corresponds to the Pasteur virus (PV). We selected PV for its good replication in cell cultures and because of the fact that there is almost no difference in the glycoprotein sequences between PV and the Mexican virus isolate. The purification method used for producing the glycoprotein was performed as recommended by the World Health Organization [25].

Western blots were performed on all serum samples on nitrocellulose stripes to which the semi-purified rabies virus was transferred [19]. After SDS-PAGE electrophoresis, rabies polypeptides were transferred onto a nitrocellulose membrane. The membrane was incubated for $2 \mathrm{~h}$, with $2 \%$ newborn bovine serum diluted in blocking reagent (Boehrringer Mannheim ${ }^{\circledR}$ ), then incubated overnight at $48{ }^{\circ} \mathrm{C}$ with the cat sera (diluted 1/25). After washing, peroxidase conjugated anti-cat (Jackson ImmunoResearch Laboratories, Inc.) antibodies were added and incubated at room temperature for $1 \mathrm{~h}$. Finally, the nitrocellulose stripes were revealed with $0.05 \%$ Diaminobenzidine (DAB) (SIGMA d-5637) with PBS plus $0.05 \% \mathrm{H}^{2} \mathrm{O}^{2}$.

\subsection{Passive transfer of cat sera to mice and viral challenge of mice}

There is evidence that the immune system from different species reacts differently to rabies vaccines. After vaccination, cats apparently develop higher titers of neutralizing antibodies than $\operatorname{dogs}[9]$.

Some comparative reports of the serological immune responses in cats refer that, after challenge, some animals do not survive despite having antibodies $^{1}$. Therefore, our first trials were done in mice

\footnotetext{
${ }^{1}$ Jakel V., Institute of Virology, Justus-LiebigUniversität Giessen, Giessen, Germany, Personal communication.
}

and, after evaluating the results, we proceeded to challenge cats. Both results are shown.

To study the average life of passively-transferred cat rabies virus neutralizing antibodies, six mice were intraperitoneally (IP) inoculated once with $0.5 \mathrm{~mL}$ of a rabies hyper-immune cat serum containing $10 \mathrm{IU}$ of neutralizing antibody. This serum was obtained from a cat previously immunized especially for this purpose (not part of the studied group). First, at day $0,0.5 \mathrm{~mL}$ of serum containing $10 \mathrm{IU}$ were inoculated to the six mice. These mice were bled on days $5,10,15,20,25$, and 30 . The sera obtained were assayed for neutralizing antibodies. We followed the technique used by Lodmell et al. [22].

After concluding the study of the average life of passively-transferred anti-rabies cat sera, we inoculated 60 mice with the experimental cat sera. They were divided into six groups of ten each. Group 1 received sera from ID-EP vaccinated cats; group 2 from IM vaccinated cats; group 3 from IN vaccinated cats; pre-immunization cat sera were applied to groups 4, 5, and 6 (negative controls) by the same routes as groups 1,2 , and 3 respectively. The titers obtained in the groups of mice that were inoculated with the pre-vaccination cat sera (negative controls) were similar to the ones obtained in mice inoculated only with virus (virus titration, not shown).

Ten days later, mice were intraplantarly challenged with 200 LD50 rabies CVS. After the viral challenge and 10,20, and 30 days later, the mice again received sera from the vaccinated cats from their respective groups. At identical intervals, groups 4,5 , and 6 received similar volumes of sera collected from cats prior to their rabies vaccination (pre-immunization sera).

The mice were observed daily and, when the first unmistakable signs of rabies were detected, they were sacrificed. Rabies virus was confirmed by direct immunofluorescent test in brain smears (FAT). This test is able to detect rabies virus with a fluorescent monoclonal antibody as described by the WHO as a standard technique [25]. The experiment ended 60 days after the viral challenge.

\subsection{Classical neutralization test in mice (CNTM)}

In order to determine if the DNA vaccine is able to protect against the homologous virus (HQ01IMSS Mexican rabies strain), a classical neutralization test in mice against the parental strain HQ01IMSS was performed. 
Cat sera from animals vaccinated by different routes were taken at day 180 . The sera obtained from cats before DNA vaccination were used as negative controls. We used female balb/c mice, 21 days old and $20 \mathrm{~g}$ average weight. Serum samples (IM, IN, ID-EP, and IM as well as negative controls) were diluted in five fold dilutions from $1 / 2.5$ to $1 / 1560$, so that after adding an equal volume of virus suspension HQ01-IMSS (50-100 LD50), the final dilutions of the serum were $1 / 5,1 / 25,1 / 125$, $1 / 625$, and $1 / 3125$. The sera and virus mixture was incubated for $1.5 \mathrm{~h}$ at $37^{\circ} \mathrm{C}$.

After incubation, groups of five mice were inoculated by the intracerebral route $(0.03 \mathrm{~mL})$ with each sera/virus mixture. Inoculated mice were checked every day and mortality was recorder from the 5 th to 21 st post-inoculation day. For each serum the dilution giving 50\% survival was obtained using the method of Reed and Muench [7].

Titers were expressed in $\mathrm{IU} / \mathrm{mL}$ by comparison with a reference serum.

\subsection{Challenge on cats}

Since the rabies virus strain used for the plasmid construction has not been previously tested for virulence, we used the CVS to challenge cats since we are sure of its lethality in this species. CVS was applied in the right masseter muscle on day 200 by inoculating $0.5 \mathrm{~mL}$ of a $1 / 30$ dilution of the CVS corresponding to $100 \mathrm{DL}$; this dilution was previously tested (data not shown). Cats were subsequently monitored and scored daily during two weeks for rabies clinical signs such as the following: changes in behavior, sensitivity disorders, swallowing difficulties, salivation, loss of appetite, paralysis, and death [29]. We tested the presence of rabies virus antigens in brain impressions from dead cats (death after challenge) by assay with an anti-nucleocapsid antibody fluorescein-labeled conjugate [32]. All cats that did not die from the challenge were euthanized at day 30 .

\section{RESULTS}

\subsection{Neutralizing antibody titers from vaccinated cats}

Cats were vaccinated with $\mathrm{pGQH}$ by different inoculation routes. Fifteen days after vaccination, neutralizing antibody titers ( $>2 \mathrm{IU}$ ) were observed in three cats vaccinated ID-EP (group C). After 30 days, the neutralizing antibody levels increased to $>3$ IU. On day 30 , two out of three cats IN vaccinated (group B) showed $>0.5 \mathrm{IU}$, except for cat No. 5 (this cat showed $>0.5$ IU after booster). On day 30, all cats, except the PBS control (group D), received a rabies DNA booster vaccination, same doses and routes (Fig. 1). Minimal levels $(>0.5 \mathrm{IU})$ of neutralizing antibodies were found in the IM vaccinated cats (group A). After the booster, the neutralizing antibody titers from the ID-EP vaccinated group increased substantially, remaining elevated for 180 days. Antibody titers from IN vaccinated cats were between 0.5 and 2.5 IU. The highest titer picks were from ID-EP vaccinated cats on day 120: in cat $8,>14 \mathrm{IU}$ and in cats 7 and $9, \geqslant 12 \mathrm{IU}$; from IN vaccinated cats on day 120: in cat 4, $>2 \mathrm{IU}$, in cat $6,>1 \mathrm{IU}$, and in cat $5,>0.6 \mathrm{IU}$ (Fig. 1).

The cats from the IM vaccinated group (group A), in spite of the booster, never reached neutralizing antibody titers higher than $0.5 \mathrm{IU}$, required and recommended as protective by the World Health Organization (WHO). Finally, cats from the PBS control group (group D), also IM vaccinated, lacked anti-rabies antibodies (Fig. 1).

\subsection{Passive transfer of cat sera to mice and viral challenge of the mice}

The in vivo protective capacity of the neutralizing antibodies elicited in cats after IM, IN, and ID-EP DNA vaccinations was evaluated by passively transferring cat sera in mice and, subsequently, challenging the mice with rabies CVS. The average life of passivelytransferred cat neutralizing antibodies was ten days. Six groups of ten mice each received cat immune sera and then the lethal challenge. After the challenge, all mice from groups 1, 2, and 3 received every ten days for two months ID-EP, IM, and IN cat sera respectively.

These mice survived and were protected (30/30 survivors).

In the same way, groups 4 (ID-EP), 5 (IM), and 6 (IN) that received sera collected from cats prior to their DNA rabies vaccination (pre-immunization sera) were not protected (0/30 survivors) 


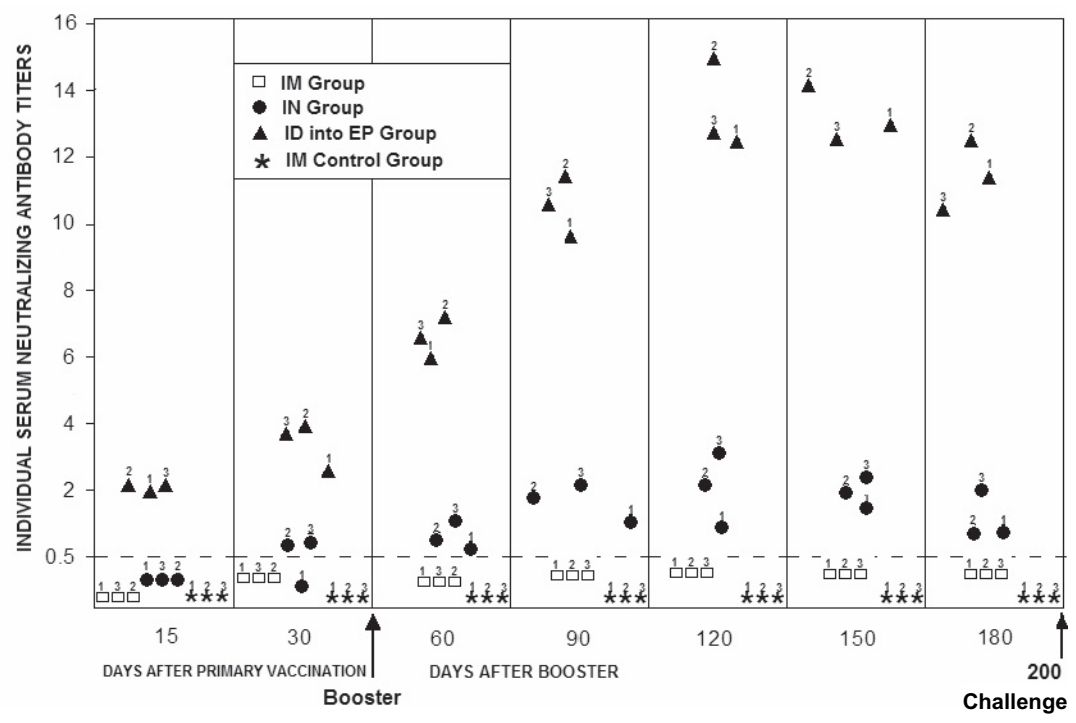

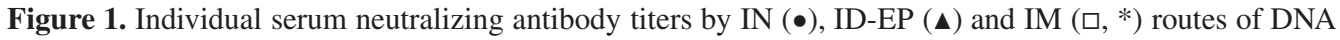
vaccination. The most effective route of inoculation for eliciting neutralizing antibodies in cats was the intradermal into ear pinnae (group 3). The intranasal by instillation (group 2) was acceptable. In contrast, in groups intramuscularly vaccinated (group 1$)$ minimal anti-rabies antibodies were obtained $(<0.5 \mathrm{IU})$ while the (group 4) control group lacked anti-rabies antibodies.

\subsection{Western blot}

Western blot tests were performed in order to recognize specific seroconversion. Only sera from IN and ID-EP vaccinated cats revealed an intense glycoprotein band (67 kDa). In the ID-EP group, all cats were tested positive to Western blot on the 15th day, and gp 67 was evidenced. In the IN group, all cats were positive on the 60th day after booster. The following tests, taken every 30 days up to the 180th day, presented the same band (gp 67). The IM group and the control group did not present this band at any time. Representative western blots from sera from cats taken on day 180 are shown in Figure 2 showing an intense glycoprotein band, gp 67 (67 KDa).

\subsection{Classical neutralization test in mice}

Using the classical neutralization test in mice, we obtained the following titers for the different groups: IM $<0.20,<0.25,<0.25 \mathrm{IU}$; IN 1, 1.25, 1.25 IU; ID-EP 7, 9, 12 IU. All control sera were negative.

\subsection{Protection against challenge with the CVS in cats}

On day 200 after vaccination, all cats were challenged with a lethal dose of CVS. All cats from the ID-EP group (C), vaccinated with one injection of plasmid plus one boost were protected against the viral challenge (Tab. II). Two of the three cats from the IN vaccinated group (B) survived the lethal challenge, cats 4 and 6 survived (Tab. II). None of the cats from the IM vaccinated group (A) survived the challenge. The non-immunized cats (group D) (cats 10,11, and 12) rapidly developed rabies. Cats 11 and 12 started presenting rabies clinical signs (salivation, anorexia, changes in tone) ten days after the challenge, and died eight days later. In cat 10 , the clinical signs started 16 days after challenge and death occurred six days later. Rabies virus nucleocapsids were detected on brain impressions by direct immunofluorescence assay after the death of these animals, including cats 1, 2, 3 (IM), and cat 5 (IN). In the surviving cats, which were sacrificed, we also tested the presence 


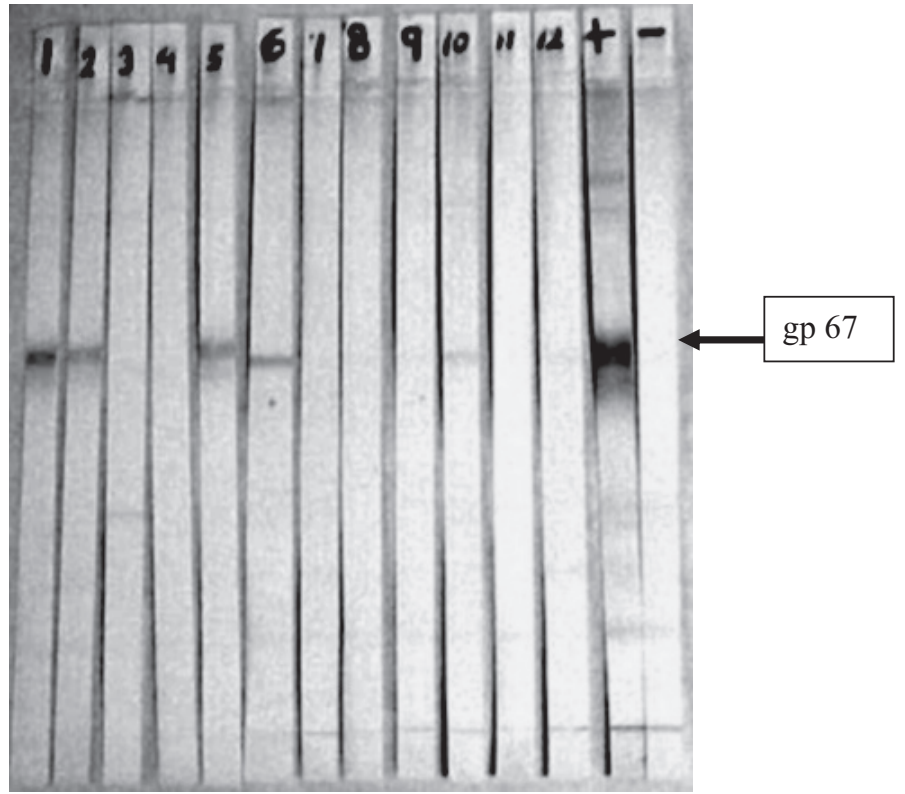

Figure 2. Representative Western blot test in cats: positive control (+), negative control (-). Cat sera taken on day 180 after booster show an intense glycoprotein band, gp 67 (67 KDa), only revealed in sera from IN (6 and 10) and ID-EP (1, 2, and 5). Cat sera taken before $\operatorname{IN}(8,9)$ and $\operatorname{ID-EP}(3,4,7)$ vaccination. Negative control sera $(11,12)$.

of rabies virus antigens on brain smears and the results confirmed that all surviving animals were negative.

\section{DISCUSSION}

In this work, a DNA vaccine against rabies was administrated to cats and we studied different inoculation routes to analyze which could be better and more efficient to promote seroconversion and protection. The results described above demonstrate that a DNA vaccine encoding rabies glycoprotein $\mathrm{G}(\mathrm{pGQH})$ elicited strong, antigen-specific immune responses in cats. On the contrary, the titers obtained by the classical neutralization test in mice CNTM using the homologous virus (HQ01-IMSS) did not correspond exactly to those obtained in the seroneutralization test in vitro using CVS as the challenge virus. Nevertheless, antibody levels obtained by the CNTM were similar to those obtained in vitro, with the highest levels corresponding to the ID-EP group and the lowest to the IM group. These results allowed us to suppose a good protection against the homologous virus.

The most effective route of inoculation for eliciting neutralizing antibodies in cats was the ID-EP. The IN route by instillation was acceptable $>0.5$ IU. In contrast, minimal antibody levels were detected in IM vaccinated cats $<0.5$ IU. The control group lacked antirabies antibodies (Fig. 1). The IM route was not good to promote an immune response in cats, as reported by Osorio et al. [29].

It seems that the IM route is less effective in cats when compared with dogs, regardless of the strain used [29].

The best results were obtained by intradermal injection into the inner surface of the ear pinna. All animals from group 3 (ID-EP) developed high neutralizing antibody levels from day 15 on (>2 IU), and the highest titer pick was on day $120,>14$ IU.

In previous studies with only one inoculation, we did not have seroconversion by the intranasal or by the intramuscular routes, only by the intradermal route into ear pinna with 
titers over 2 IU on day 60. After analyzing these results, we decided to repeat the experiments with a booster on day 30 .

According to Osorio et al. [29], these results clearly show that methods of delivery and sites of vaccination influence neutralizing antibody responses in cats immunized with different anti-rabies DNA vaccines.

Other studies made in mice demonstrated that ear pinna is an excellent site for initiating immune responses with a DNA vaccine [15].

Forg et al. [15] used the bacterial lacZ gene as a model and reported that antibody and CTL responses from mice injected in ear pinna exceeded those from mice injected in muscle or abdomen dermis.

The superiority of the ear pinna as a vaccination site is ascribed to its unique immunological features that focus the concentration of processed antigens in a restricted area, which is connected to a major draining lymph node. It is thought that the concentration of processed antigens results in an enhanced stimulation of $\mathrm{T}$ lymphocytes by antigen-loaded dendritic cells [4].

Recently, a single intramuscular or intranasal immunization in mice with a recombinant canine adenovirus expressing the rabies virus $\mathrm{G}$ protein (CAV2-RVG) induced protective immunity in a dose-dependent manner, regardless of the administration route [21].

Another recombinant canine adenovirus type 2 encoding the rabies virus glycoprotein (CAV-E3delta-CGS) applied subcutaneously to dogs, produced effective neutralizing antibodies after one inoculation and a stronger anamnestic immune response after booster injection [20].

Due to the significant results obtained in cats that were ID-EP vaccinated, we studied the histology of a normal cat ear in order to explore the tissue and we observed a vast vascular draining site with many lymphocytes. Some dendritic cells (DC) were evidenced in cat ear histology cuts but, since there is not a specific cat DC marker, we used CD1-A, which detects human DC.

We found some DC in ear pinna cuts and we believe that the DC participation is implicated in the possible set up of the detected DC, which arrive to the nearest ganglions and trigger the immune response. Nevertheless, more studies will be made in order to recognize which cells are involved and understand why the humoral immune response is so high using the ID-EP route.

The intranasal route was revealed as acceptable to promote seroconversion but a delayed immune response was observed. On day 30 , two of the three cats from the IN group showed over $0.5 \mathrm{IU}$ of neutralizing antibodies but on day 60 all cats had already seroconverted. Rabies DNA booster vaccination was administrated on day 30 and the highest titer pick was on day 120 (>2 IU). The time required to promote neutralizing antibodies by the IN route could be lessened if the DNA vaccine was combined with a mucosal specific adjuvant, which could increase the immune response.

The nasal administered DNA plasmid is absorbed by the systemic circulation and it is distributed to different body tissues, including the brain [28].

The mechanism by which a large DNA plasmid molecule is absorbed remains unknown, although a DNA plasmid may interact with the epithelial membrane and transiently affect tight junctions. Alternatively, a transportation system facilitating the absorption of a DNA plasmid through the nasal mucosa may be operating [14].

Some studies using enterotoxins as adjuvants have been reported. For example, an antigen together with a cholerae toxin or heatlabile $E$. coli enterotoxin, administered intranasally, leads to the localization of antigen and toxin in the olfactory nerve and the olfactory bulb for an extended period [14]. The IN vaccination route was successful when used in humans against the influenza virus. However, the risk of Bell's palsy [27] was reported when this type of vaccine was applied in combination with $E$. coli toxin.

There are some advantages in the administration of a DNA rabies vaccine by the IN route: simple administration (no need for injections), small doses required, and activation of mucosal and systemic immune responses.

The risks of a genetic vaccination have been previously reported in the literature. The 
general risks could be the following: DNA integration into the vaccinated individual, and production of anti DNA antibodies. In a previous study in mice, we observed that the antigen could be produced in the central nervous system (olfactory lobules) when a DNA vaccine is applied by the intranasal route, with no known consequences up to date. However, further studies should be done.

IN vaccination seems attractive due to its easy application and mucosal protection. This form of vaccination could also be advantageous in domestic animal vaccination campaigns for its less stressing application than the potential route. It could also be interesting for Latin American countries, where bat bite cases have been reported in wild and domestic animals [12] and also in humans [11]. It is a fact that rabies virus aerial cycle strains infect terrestrial animals, as previously mentioned in the Quintana Roo, Mexico case, in 2006 [18].

The main advantage of using DNA vaccines over traditional live ones is that there is no contamination with viruses that could be disseminated in the environment and reproduced in susceptible animals.

Acknowledgements. This work was partially supported by a grant of the CONACYT of Mexico (Z-006), and a grant of Coordinación de Investigación en Salud of Instituto Mexicano del Seguro Social (2006/6/I/316). We thank MDV Monica GuevaraCanizal, and MDV Elizabeth Hernández-Rodríguez for their medical assistance, and also Miguel GarciaHernández for their excellent technical assistance and for their help with the animal care.

\section{REFERENCES}

[1] Acha P.N., Arambulo P.V., Rabies in the tropics history and current status, in: Kuwert E., Merieux C., Koprowski H., Bogel K. (Eds.), Rabies in the Tropics, Springer-Verlag, New York, USA, 1985.

[2] Aguilar-Setién A., León-Campos Y., TesoroCruz E., Kretschmer R., Brochier B., Pastoret P.P., Vaccination of vampire bats using a recombinant vaccinia-rabies virus, J. Wildl. Dis. (2002) 38:539544.

[3] Aguilar-Setién A., Aguila-Tecuatl H., Tesoro-Cruz E., Ramos-Ramírez L., Kretschmer R., Preservation of rabies virus RNA from brain tissue using glycerina, Trans. R. Soc. Trop. Med. Hyg. (2003) 97:1-3.

[4] Akbari O., Panjwani N., Garcia S., Tascon R., Lowrie D., Stockinger B., DNA vaccination: transfection and activation of dendritic cells as key events for immunity, J. Exp. Med. (1999) 189:169-178.
[5] Atanasiu P., Perrin P., Microméthode immunoenzymatique de titrage des anticorps antirabiques : utilisation de la glycoprotéine rabique et de la protéine conjuguées à la peroxydase, Ann. Inst. Pasteur Microbiol. (1979) 7:213-220.

[6] Bahloul C., Jacob Y., Tordo N., Perrin P., DNA-based immunization for exploring the enlargement of immunological cross-reactivity against the lyssaviruses, Vaccine (1998) 16:417-425.

[7] Bourhy H., Sureau P., Laboratory methods for rabies diagnosis, Institut Pasteur, Paris, France, 1999.

[8] Brochier B., Blancou J., Thomas I., Languet B., Artois M., Kieny M.P., Lecocq J.P., Costy F., Desmettre P., Chappuis G., Pastoret P.P., Use of recombinant vaccinia-rabies glycoprotein virus for oral vaccination of wildlife against rabies. Innocuity to several non target bait consuming species, J. Wildl. Dis. (1989) 25:540-547.

[9] Cliquet F., Verdier Y., Sagné L., Aubert M., Schereffer J.L., Selve M., Wasniewski M., Servat A., Neutralizing antibodies titration in 25000 sera dogs and cats vaccinated against rabies in France, in the framework of the new regulations that offer an alternative to quarantine, Rev.-Off. Int. Epizoot. (2003) 22:857-866.

[10] Cupillard L., Juillard V., Latour S., Colombet G., Cachet N., Richard S., Blanchard S., Fischer L., Impact of plasmid supercoiling on the efficacy of a rabies DNA vaccine to protect cats, Vaccine (2005) 23:1910 1916.

[11] Da Rosa E.S., Kotait I., Barbosa T.F., Carrieri M.L., Brandão P.E., Pinheiro A.S., Begot A.L., Wada M.Y., de Oliveira R.C., Grisard E.C., Ferreira M., Lima R.J., Montebello L., Medeiros D.B., Sousa R.C., Bensabath G., Carmo E.H., Vasconcelos P.F., Bat-transmitted human rabies outbreaks, Brazilian Amazon, Emerg. Infect. Dis. (2006) 12:1197-1202.

[12] Delpietro H., Fábregas F., Díaz M., Riesgo de transmisión rábica en la predación de quirópteros por carnívoros domésticos, Vet. Argentina (1987) 42:119124.

[13] Donnelly J.J., Ulmer J.B., Shiver J.W., Liu M.A., DNA vaccines, Ann. Rev. Immunol. (1997) 15:617648.

[14] Eriksson A.M., Schon K.M., Lycke N.Y., The cholera toxin-derived CTA1-DD vaccine adjuvant administered intranasally does not cause inflammation or accumulate in the nervous tissues, J. Immunol. (2004) 173:3310-3319.

[15] Forg P., Von Hoegen P., Dalemans W., Schirrmacher V., Superiority of the ear pinnae over muscle tissue as site for DNA vaccination, Gene Ther. (1998) 5:789-797.

[16] Frey A., Neutra M.R., Targeting of mucosal vaccines to Peyer's patch M cells, Behring Inst. Mitt. (1997) 98:376-389.

[17] Gallegos Gallegos R.M., Espinosa Larios E.L., Ramos Ramirez L., Kretschmer S.R., Aguilar Setien 
A., Rabies veterinary virus vaccine produced in BHK21 cells grown on microcarriers in a bioreactor, Arch. Med. Res. (1995) 26:59-63.

[18] Gómez-Carro S., Ortiz-Alcaraz M.L., JiménezRíos E., De Los Santos-Briones S., Marín-Pech E., Estudio de caso de rabia humana transmitida por murciélago hematófago en Yucatán, México, Rev. Biomed. (2006) 17:118-122.

[19] Grassi M., Wandeler A., Peterhans E., Enzymelinked immunosorbent assay for determination of antibodies to the envelope glycoprotein of rabies virus, J. Clin. Microbiol. (1989) 27:899-902.

[20] Hu R., Zhang S., Fooks A.R., Yuan H., Liu Y., Li H., Tu C., Xia X., Xiao Y., Prevention of rabies virus infection in dogs by a recombinant canine adenovirus type- 2 encoding the rabies virus glycoprotein, Microbes Infect. (2006) 8:1090-1097.

[21] Li J., Faber M., Papaneri A., Faber M.L., McGettigan J.P., Schnell M.J., Dietzschold B., A single immunization with a recombinant canine adenovirus expressing the rabies virus $G$ protein confers protective immunity against rabies in mice, Virology (2006) 356:147-154.

[22] Lodmell D.L., Parnell M.J., Weyhrich J., Ewalt L.O., Canine rabies DNA vaccination: a single-dose intradermal injection into ear pinna elicits elevated and persistent levels of neutralizing antibody, Vaccine (2003) 21:3998-4002.

[23] Lodmell D.L., Ewalt L.C., Parnell M.J., Rupprecht C.E., Hanlon C.A., One-time intradermal DNA vaccination in ear pinnae one year prior to infection protects dogs against rabies virus, Vaccine (2006) 24:412-416.

[24] Loza Rubio E., Aguilar Setién A., Bahloul C., Brochier B., Pastoret P.P., Tordo N., Discrimination between epidemiological cycles of rabies in Mexico, Arch. Med. Res. (1999) 30:144-149.

[25] Meslin F.X., Kaplan M.M., Koprowski H., Laboratory techniques in rabies, 4th edition, World Health Organization, Geneva, Switzerland, 1996.

[26] Meslin F., Global review of human and animal rabies, Rabies: guidelines for medical professionals, Veterinary Learning Systems, Trenton, NJ, USA, 1999.

[27] Mutsch M., Zhou W., Rhodes P., Bopp M., Chen R.T., Linder T., Spyr C., Steffen R., Use of the inactivated intranasal influenza vaccine and the risk of Bell's palsy in Switzerland, N. Engl. J. Med. (2004) 350:896903.

[28] Oh Y.K., Kim J.P., Hwang T.S., Ko J.J., Kim J.M., Yang J.S., Kim C.K., Nasal absorption and biodistribution of plasmid DNA: an alternative route of DNA vaccine delivery, Vaccine (2001) 19:4519-4525.
[29] Osorio J.E., Tomlinson C.C., Frank R.S., Haanes E.J., Rushlow K., Haynes J.R., Stinchcomb D.T., Immunization of dogs and cats with a DNA vaccine against rabies virus, Vaccine (1999) 17:1109-1116.

[30] Paoletti E., Applications of pox virus vectors to vaccination: an update, Proc. Natl. Acad. Sci. USA (1996) 93:11349-11353.

[31] Pastoret P.P., Brochier B., Epidemiology and control of fox rabies in Europe, Vaccine (1999) 17:17501754.

[32] Perrin P., Techniques for the preparation of rabies conjugates, in: Meslin F.X., Kaplan M., Koprowski H. (Eds.), Laboratory techniques in rabies, 4th edition, World Health Organization, Geneva, Switzerland, 1996.

[33] Perrin P., Jacob Y., Aguilar-Setién A., Loza-Rubio E., Jallet C., Desmézières E., Aubert M., Cliquet F., Tordo N., Immunization of dogs with a DNA vaccine induces protection against rabies virus, Vaccine (1999) 18:479-486.

[34] Rudmann D.G., Van Alstine W.G., Doddy F., Sandusky G.E., Barkdull T., Janovitz EB., Pulmonary and mediastinal metastases of a vaccination-site sarcoma in a cat, Vet. Pathol. (1996) 33:466-469.

[35] Rupprecht C.E., Hamir A.N., Jhonston D.H., Koprowski H., Efficacy of a vaccinia-rabies glycoprotein recombinant virus vaccine in raccoons (Procyon lotor), Rev. Infect. Dis. (1988) 10:S803-S809.

[36] Schneider L.G., Rabies virus vaccines, Dev. Biol. Stand. (1995) 84:49-54.

[37] Smith J.S., Yager P.A., Baer G.A., A rapid fluorescent focus inhibition test (RFFIT) for determining rabies neutralizing antibodies, in: Meslin F.X., Kaplan M.M., Koprowski H. (Eds.), Laboratory Techniques in Rabies, 4th edition, World Health Organization, Geneva, Switzerland, 1996.

[38] Tesoro-Cruz E., Hernández-González R., AlonsoMorales R., Aguilar-Setién A., Rabies DNA vaccination by the intranasal route in dogs, Dev Biol (Basel) (2006) 125:221-231.

[39] Wunner W.H., Dietzschold B., Curtis P.J., Wiktor T.J., Rabies subunit vaccines, J. Gen. Virol. (1983) 64:1649-1656.

[40] Xiang Z.Q., Spitalnik S., Tran M., Wunner W.H., Cheng J., Ertl H.C., Vaccination with a plasmid vector carrying the rabies virus glycoprotein gene induces protective immunity against rabies virus, Virology (1994) 199:132-140.

[41] Xiang Z.Q., Yang Y., Wilson J.M., Ertl H.C., A replication defective human adenovirus recombinant serves as a highly efficacious vaccine carrier, Virology (1996) 219:220-227. 